This PDF is a selection from a published volume from the National Bureau of Economic Research

Volume Title: The Inflation-Targeting Debate

Volume Author/Editor: Ben S. Bernanke and Michael Woodford, editors

Volume Publisher: University of Chicago Press

Volume ISBN: 0-226-04471-8

Volume URL: http://www.nber.org/books/bern04-1

Conference Date: January 23-26, 2003

Publication Date: December 2004

Title: What Has Inflation Targeting Achieved?

Author: Mervyn A. King

URL: http://www.nber.org/chapters/c9554 


\title{
What Has Inflation \\ Targeting Achieved?
}

\author{
Mervyn King
}

In the United Kingdom, in rather the same way as Marvin Goodfriend described the U.S. experience, we went through a postwar period of first stop/ go and then three severe recessions. There was the "great inflation" in which inflation peaked at 27 percent in the mid-1970s - and averaged 13 percent a year right through the whole of that decade. It even averaged over 7 percent a year right through the 1980s under Mrs. Thatcher. Only since 1992 has inflation been consistently below 4 percent, and in fact it has averaged a fraction under 2.5 percent of our target for the past ten years, with growth averaging 2.5 percent a year and a little above the historical trend. Inflation has been low and stable. Unemployment came down from double-digit levels to 5 percent. And there have been forty-two consecutive quarters of positive economic growth, which I think is unprecedented, at least in our history.

But the question is, was inflation targeting necessary to that achievement? Whatever the answer to that question, I do think that inflation targeting made our job easier by reducing the cost of making the right decisions. Why is that? I think that monetary stability, or macroeconomic stability more generally, is a bit like healthy living: you need to find a sustainable way of doing it. There is no point alternating between a crash diet and bingeing. That is the boom/bust syndrome. The key is to find a way of setting policy that can be sustained. I think it is helpful to devise procedures, whether they be thought of as monetary policy rules or whether they are institutions that remove temptation, to help the weaker brethren explain themselves to others.

Mervyn King is governor of the Bank of England and is chairman of the Monetary Policy Committee. 
Let me very briefly summarize what happens in the United Kingdom. We have a target for consumer price inflation, which is a measure of retail price inflation excluding the interest component on mortgages - the socalled RPIX inflation - and we are instructed to aim at 2.5 percent. And we are meant to aim for that at all times. It is a symmetric target; that is quite clear in the remit. That is relevant, I think, to the paper by Jonas and Mishkin (chap. 9, which I will discuss later), in which they see some problems in transition economies from the lack of symmetry.

Crucially, this target is set by the government. We do not set it ourselves at the Bank of England. It is given to us by government. The decisions on interest rates are then made by the Monetary Policy Committee, which meets once a month by statute on fixed dates, all announced well in advance. There are nine members of the committee, each with one vote. Dissenting votes are common. It is rare to have a unanimous vote from the committee.

We spend a long time on the forecast procedure using a range of models. Sometimes I think that we have more econometric models than one could possibly want. In the end, however, the judgment of the committee has to play a key role, and we can come back to that later. We publish our minutes thirteen days after the announcement of the decision. The minutes contain the voting pattern, and they contain a description of the arguments that were given during the discussion to justify views on particular parts of the analysis or indeed on the final judgment on interest rates. Once a quarter, we publish a formal forecast for inflation in our Inflation Report.

This systematic process should be contrasted with what went before in the United Kingdom. No notice of when policy decisions would be made was given. The financial markets had no notice of when interest rates would be decided, so it could be any day. That certainly kept them glued to the screens.

Of course, in this setting a serious economic discussion did not carry much weight. It was the ability to swing the argument on the basis of what happened at the time. And politics intruded a very great deal. So what has happened in Britain is that we switched, for better or worse-and I think it is clearly for the better - to a much more systematic professional procedure, which you have had in the Federal Open Markets Committee (FOMC) for a very long time. Now, I think this may well be part of the success of inflation targeting in other countries as well.

There are four key points I want to make. One is about constrained discretion and inflation expectations. A second is about inflation targeting and the committee process itself. A third is about transparency and accountability, and a fourth is one that Martin Feldstein has alluded to, which is that inflation targeting does not give all the answers. That is, there are many difficult aspects of the economic outlook that are all about serious economics and discussing what is likely to happen in the future, but 
that are made no easier by having an inflation-targeting framework than they would be by any other framework.

On the first point, constrained discretion and inflation expectations, any monetary policy can be thought of as a combination of an inflation target in the medium term and a response to shocks as they occur. In that sense, any coherent policy reaction found can be described as inflation targeting. I like to see inflation targeting as being about - to use Ben Bernanke and Frederic Mishkin's phrase-constrained discretion." It sets up a process in which the Central Bank has to explain what it is doing. Now, this has two implications, I think. One is that it is easier, I believe, to influence inflation expectations. Certainly part of our success has been that we have brought inflation expectations down; whether you measure them by bond yields, index-linked versus conventional yields, or surveys, inflation expectations in Britain are now pretty well anchored on the 2.5 percent target. And that makes monetary policy easier by giving monetary policy a bit more time to respond. We are not worried that an inflationary shock is likely to lead immediately to an upward revision or downward revision of inflation expectations, feeding through very quickly as it might have done before into inflation expectations, wage bargaining, and then prices. This point is stressed in the paper by Orphanides and Williams (chap. 5), which we are going to discuss. It matters because if you let inflation expectations drift too far away from the target, you can end up in quite serious difficulty with a costly process to bring them back again.

Another aspect of our process is that it is one in which economists have some comparative advantage. This is unlike the old British amateur tradition, in which mystery and mystique were the essence of central banking. In the United Kingdom, this has been something of a sea-change. This may or may not be true elsewhere. In Britain, however, the central bank is now seen as an institution that is about making professional economic judgments in a way that it was not before, and I think that really matters.

I have always thought of inflation targeting as a way of implementing the optimal policy reaction function, setting the optimal policy by means of constrained discretion within the inflation-targeting framework. In chapter 2, Lars Svensson and Michael Woodford are going to explain why it is just a bit more complicated than I used to think. Nevertheless, I still think that the idea of a framework is to get as close as possible to what you, the theorist, think of as optimal monetary policy. This should be done in a way that forces the central bank to explain and, by accountability, helps to keep it on track and make the right decisions. That is the first point.

The second point is the committee process. This is a pure observation based on the U.K. experience. Even with nine professional economists, my belief is that in a committee without a clear objective there would be scope for people to set their own agenda. Members might try to argue that their view of the objective is the right one and other people's the wrong one. This 
could divert the committee from spending its time discussing the state of the economy and the technical judgments needed to hit a given target.

What is clearly true about our Monetary Policy Committee, and I do not think this was obvious ex ante, is that the entire discussion is focused on a technical economic judgment about what it is necessary to do to hit the inflation target. Now, you can talk about whether the target is desirable or not, but in terms of making sure that people around the table do what they are supposed to do, this is highly effective. Many committees I have sat on have had the property that people often try to gain leadership of the community by moving toward the center, forming a consensus in which they exercise some leadership. They are never judged on whether the outcome of the decision is good or bad; instead, they are judged according to whether they are strong committee people.

Individual accountability, allied to the fact that the target is given to us from outside, means that the nature of our discussions is absolutely, solidly focused on the state of the economy and what we need to do to interest rates to keep inflation on track to hit the target. We have a two-day meeting in which the first day is about the diagnosis of the economy, and the second day is the treatment, the level of interest rates. Those meetings are more successful than any other meetings I have been to at committees because there is a very clear objective.

The third point concerns transparency, accountability, and legitimacy. Our split between the government setting the target and the central bank making decisions is of course instrument independence, to use Stan Fischer's phrase. But we go out around the country and to Parliament to explain why our policy decisions will help to meet the target, and having a clear target gives us a natural focus. I would say that this delegation of decisions to the Monetary Policy Committee, which actually came in May 1997, has in fact proved very popular. This was not to be expected. Many people thought that no government would make the Bank independent because Parliament would complain that it had lost control. The press would complain that there was no democratic mandate and that people would feel that we were unaccountable.

That has turned out not to be the case. First of all, the business community likes to feel that there is a group of people who actually know what they are talking about setting monetary policy. In fact, it is the only thing we are supposed to be talking about. Second, we are accountable in welldefined ways, and I think that the pressure we have been put under to explain ourselves has actually benefited us.

One of the great benefits of having a committee is that people can see what the issues are, and even if members of the committee disagree and put different arguments, I think the great success of our system and that which has been a real lesson to us has been never to claim that the decision was obvious. Always point out that there were arguments on each occasion for 
and against the action that was taken, explain what the arguments were, and then everyone feels that at least the relevant arguments are being put on the table.

Finally, on the last point, inflation targeting, as I said, is a way of thinking about policy. It is not an automatic answer to all the difficult policy questions. I think the asset price question is probably the best example of that. We have faced major asset price movements, so it is not as if we have not actually been challenged in our framework so far. We have had a rise in the effective exchange rate index of more than 20 percent, both nominal and real, in the early part of the period, which has persisted almost until now. We had the sharp rise in stock prices and then a sharp fall in stock prices. More recently, we have had increases in house prices of between 25 and 30 percent.

I think the difficulty is to work out what these movements mean for the risks in the future. My feeling is that any policy decision has to take into account the entire distribution of future outcomes for inflation and output, and not just the expected values in some exact future period. In my speech in November 2003 at the London School of Economics, I talked about the fact that inflation targeting as a framework can, I think, provide a way to discuss this. Sharp asset price movements raise risks that mean there is a potential trade-off between the risk of a small shortfall of the inflation target now relative to a bigger risk of a large deviation of inflation from the target in the future. In the conventional discussion, there is a trade-off between the volatility of inflation and the volatility of output. Similarly, in choosing the horizon over which you bring inflation back to the target, there is a choice about whether to accept in the short run inflation a little short of the inflation target, but to do so knowingly, against the risks involved in a potentially large deviation of inflation from target further ahead at a longer horizon.

I think this is a tricky question to which there is no simple answer. It is not something that is peculiar to inflation targeting, and other frameworks have other methods of dealing with it. But I don't think it is inconsistent with inflation targeting, although it does merit some separate discussion.

We have spent a good deal of time and effort building a constituency for low inflation. This involves trying to build public support for low inflation, which I think is important because of the very interesting work done on Germany showing that the more distant were the hyperinflation episodes, the more the younger generations lacked commitment to low inflation. Thus, you cannot just rely on the memory of boom and bust in the past to keep people committed to low inflation. We need a positive program to persuade people, and having a clear inflation target has helped. Like the Federal Reserve, we have our competition for schools, and ours is called Target 2.5.

Martin Feldstein had six issues to discuss, whereas I have five questions 
that I would like to put. First, I would be interested to know whether people would agree that inflation targeting makes it easier for the weaker brethren - that is, most people in central banking - to do the right thing.

Second, why is it that countries that have adopted inflation targeting are generally very happy with it? Is it just that they have benefited from a very benign period, or have they found this a sustainable, healthy way of living?

Third, what is it that a central bank should be trying to communicate? Is it a policy reaction function, or is it something more complicated? Is it what central banks are learning about the economy, in addition to a policy reaction function? I often think that Alan Greenspan's speeches are almost a conversation with the public about the issues that arise when thinking about the economy. I think we have tried to do some of that, too.

Fourth, how serious are the problems posed by issues such as asset price inflation and about the horizon over which inflation should be brought back to target? Finally, how can we focus the attention of both decision makers and the public much more on the risks around the central projection than on just the central projection of a forecast for the expected value of our projection? 